\title{
Correspondence
}

\section{Patient satisfaction}

To the Editor:

In their survey of patient satisfaction with intravenous PCA or epidural morphine, Egan and Ready conclude that satisfaction is very high with both modalities, but the perceived advantages and disadvantages differ. ${ }^{1}$ While I share the authors' enthusiasm for both techniques, I feel there are some methodological concerns which may limit the validity of the conclusions.

The authors reported differences between the two patient groups with respect to advantages, disadvantages and patient satisfaction. I question if such comparisons are valid when the demographics of the two groups studied are so clearly different; the PCA group was, on average, nine years younger than the epidural group, and presumably represented a different case mix. Although not reported, it is reasonable to assume that the patients undergoing more serious surgery were also more likely to receive epidural narcotics postoperatively. Within each group the authors have identified relative advantages and disadvantages perceived by the patients. However, on the basis of the very considerable demographic differences, I would argue that no valid between-group comparisons of PCA versus epidural narcotics are possible.

The authors also state that " ... patients converted from one form of therapy to the other for any reason were excluded." This would seem to bias the reported satisfaction scores, since the only obvious reason for a change in therapy is patient or physician dissatisfaction. It would be useful to know how often this occurred.

Quite rightly, Egan and Ready point out that, "Although patients willingly offer (satisfaction) ratings, it is by no means clear what such ratings represent." This is further illustrated in a randomized prospective study of PCA versus im morphine in patients following hip arthroplasty. ${ }^{2}$ In both groups, the patients reported satisfaction scores of approximately nine out of ten, yet pain control assessed using visual analogue scores for both intensity and distress was often inadequate. In fact, the highest satisfaction score was coincident with the worst reported pain. Barring the most egregious errors, one suspects that if your patient likes you, reported satisfaction will be high.

\footnotetext{
Richard C. Etches MD FRCPC

Department of Anaethesia

University of Alberta Hospitals
}

8440-112 Street

Edmonton, Alberta T6G 2B7

\section{REFERENCES}

1 Egan KJ, Ready LB. Patient satisfaction with intravenous PCA or epidural morphine. Can J Anaesth 1994; 41: 6-11.

2 Duggleby W, Lander J. Patient-controlled analgesia for older adults. Clinical Nursing Research 1992; 1: 107-13.

\section{REPLY}

We appreciate the thoughtful comments made by Dr. Etches regarding our recent publication.' While we want to answer his concerns about research design, we heartily support his concluding statement that how patients feel about their pain therapist influences their level of satisfaction with the care they receive. Although Dr. Etches may see this as confounding the data, we, on the contrary, believe that the interaction between advanced medical technologies and the human responsiveness of the pain therapist produces the most powerful force to allay pain and suffering. The major thrust of our paper was an initial attempt to identify sources of satisfaction relating to the use of two highly advanced technologies, patient controlled analgesia and epidural opioid analgesia, such that the different modalities can be chosen more appropriately for individual patients before surgery. It is not enough merely to assess levels of satisfaction; we have to select the best techniques for patients who have different psychological needs. Indeed, the "bias" in our study as defined by Dr. Etches was a result of patient selection already incorporated in our practice.

It is true that there was a difference of nine years in the mean ages of the PCA group and the epidural group. This is a reflection of our experience with these modalities. We have recognized that younger patients tend to appreciate active participation in their care including the element of control that PCA provides, while elderly patients tend to prefer the more passive role associated with epidural analgesia. The bias in our study, if any, was toward recommending on a patient-by-patient basis what clinical experience has taught us would be most successful. The age difference in the two groups does not mean, in the case of our patients, that more serious surgery was performed in the epidural group as Dr. Etches has suggested. We believe that the between-group comparisons are valid since each group was offered the therapeutic approach that, on average, experienced pain therapists have found to be best suited to patients in varying clinical situations.

Patients converted from one form of therapy to another were excluded from our study. Although we did not present data on the frequency of this event, we are able to describe the most common reason for such a change. In an anaesthesia residency training programme, epidural catheters are inserted by a large number of trainees with varying levels of expertise. As a result, technical problems with epidural catheters were sometimes seen in patients in the study. When patients with epidurals did not achieve adequate analgesia, efforts to rectify the problem were made. These efforts included retesting the 
catheter with a local anaesthetic. When it was determined that there was no sensory block or when a "spotty" or unilateral block was seen, the catheter was replaced (in which case the patient was included in the study), or the catheter was abandoned and PCA was started (in which case the patient was not included in the study). With this approach we chose to compare only patients with appropriately functioning epidural catheters with $P C A$ patients.

Kelly J. Egan PhD

L. Brian Ready MD

University of Washington

Medical Center, RC-95

Room EE405

Seattle, WA 98195

REFERENCE

1 Egan KJ, Ready LB. Patient satisfaction with intravenous PCA or epidural morphine. Can J Anaesth 1994; 41: 6-11.

\section{Drug labelling}

To the Editor:

With the ever-increasing number of drugs available in the anaesthesia armamentarium, the need for clear, easy to identify drug labelling has been recently reinforced. ${ }^{1-3}$

In their report Drs. Orser and Oxorn outline a potentially fatal medication error, the treatment and their subsequent investigation and follow-up. One of their recommendations suggest "Whenever possible, each drug available on the anaesthetic cart should have distinct and unique markings." I could not agree more. There is presently a Canadian standard; Canadian Standards Association (CSA) \#Z327-M91 Standard for User Applied Drug Labels in Anaesthesia and Critical Care ${ }^{4}$ for anaesthesia drug syringe labels which is similar to the standard of the American Standards for Testing and Materials (ASTM) D4774-93..$^{5}$ This standard specifies design requirements for size, colour, pattern, shape and typeface used on labels applied to unlabelled syringes filled by users to identify their contents. The original intention of the standard was not to include manufacturer applied labels to drug vials. However, it may potentially be used as a framework for future manufacturer-applied drug labels.

Another ASTM Standard, D4267-89, ${ }^{5}$ which I believe has not been implemented in Canada, requires drug names on glass ampoules to be printed in such a way that the drug's name and dosage is clearly visible at arm's length and has a contrasting colour background.

These standards were established to try to reduce the risk of accidental administration of a wrong drug and improve patient safety. Hopefully implementation of a standard for manufacturer-applied drug labels may provide some consistency in drug labelling so that future disasters may be averted.

Steven Dain MD FRCPC

Saint Joseph's Health Centre

London

REFERENCES

1 Orser $B A$, Oxorn $D C$. An anaesthetic drug error: minimizing the risk. Can J Anaesth 1994; 41: 120-4.

2 Boldt C. Safety hazard - Sabex drug labels (Letter). Can J Anaesth 1994; 41: 75-6.

3 Dain SL. Safety hazard - Abbott drug labels (Letter). Can J Anaesth (in press).

4 Canadian Standards Association, 176 Rexdale Blvd., Toronto, Ontario M9W 1R3.

5 Annual Book of ASTM Standards, American Society of Testing and Materials, 1916 Race Street, Philadelphia PA 19103.

\section{Anaesthetic drug error}

To the Editor:

We read with interest the clinical report "An anaesthetic drug error: minimizing the risk" by Beverley $A$. Orser et al. $;$ and are in agreement with the recommendations of the Risk Management Team.

However, instead of each country having its own programme for reporting of drug packaging problems, we suggest a single global organization. A drug manufactured in one country may not be used only in that country. For example in our institute we use Dopaplus ${ }^{\circledR}$ (dopamine) manufactured by Chemil Farmaceuticis, Milano, Italy and Nitrocure ${ }^{\circledR}$ (nitroglycerin) manufactured by Pharma Hamein GmbH Hamein Wesser in West Germany. Both the drugs are in $5 \mathrm{ml}$ glass vials and are of the same size, shape and brown colour. They look and even feel very similar.

A. Agarwal MD

S. Kaushik DA MS MNAMS

A. Maheshwari MD

Department of Anaesthesia and Critical Care Medicine SGPGIMS, Lucknow, India

\section{REFERENCE}

1 Orser $B A$, Oxorn $D C$. An anaesthetic drug error: minimizing the risk. Can J Anaesth 1994; 41: 120-4. 